\title{
Weapon System Operational Capability
}

\author{
R. Guo \\ 667\#, Jiefang Road, Zhongshan District, Dalian City, China
}

\begin{abstract}
As operational capability of the weapon system can be varied with each fire, it proposes operational capability evaluation method for the weapon system, afterwards it proposes operational capability evaluation method for the weapon fire taking the impact indicators such as single target detection probability of shipborne early-warning radar into account.
\end{abstract}

Keywords-weapon system; operational capability; evaluation

\section{INTRODUCTION}

All manuscripts must be in English. Please keep a second copy of your manuscript in your office (just in case anything gets lost in the mail). When receiving the manuscript, we assume that the corresponding authors grant us the copyright to use the manuscript for the book or journal in question. Should authors use tables or figures from other Publications, they must ask the corresponding publishers to grant them the right to publish this material in their paper.

Operational capability evaluation of weapon system is an important elementary work for the combat employment of the weapon system. Zhao C.G.1 proposes the exponential method for the operational capability evaluation, Jia C. 2 proposes the queuing method. These methods can not assess the operational capability evaluation indicators in an operational environment. Although Ma L.T.3 proposes fuzzy comprehensive method in an operational environment, this method can not take the impact indicators of the operational capability such as single target detection probability of shipborne early-warning radar, control probability of shipborne combat command system, single target acquisition probability of tracking radar, single target damage probability into account, and still needs to assess the operational capability evaluation indicators of the weapon system.

Therefore, the next step in the operational capability evaluation method for weapon system is to take the above impact indicators into account, which can assess the operational capability evaluation indicators of single weapon system onboard single surface ship in an operational environment.

\section{OPERATIONAL CAPABILITY EVALUATION METHOD FOR THE WEAPON SYSTEM}

Once weapon system is in total failure or done with the designated air defense mission, the operational phase of the weapon system which includes Ns times of weapon fires is over, $\mathrm{Ns} \geq 1$.

Usually the operational capability of the weapon system can be varied with each fire, it should firstly construct the operational capability evaluation model of the weapon fire, which can obtain the operational capability evaluation indicators of the weapon fire such as single target damage probability, multi-target damage probability, expected target damage. Through the addition operation of the above evaluation indicators, it can obtain the operational capability evaluation indicators of the weapon system such as single target damage probability, multi-target damage probability, expected target damage, number of times for firing at single target.

\section{OPERATIONAL CAPABILITY EVALUATION METHOD FOR THE WEAPON FIRE}

In the process of the weapon fire, there are more than one target to fire at. It should firstly construct the capability evaluation model of firing at single target to assess single target damage probability, and then construct the capability evaluation model of the weapon fire.

\section{CAPABILITY EVALUATION MODEL OF FIRING AT SINGLE TARGET}

Usually shipborne early-warning radar delivers target information to shipborne combat command system after it detected targets. Afterwards shipborne combat command system is in the control process of track processing, Identification Friend or Foe (IFF), threat estimation and so on. In the end, shipborne combat command system offers target designation to weapon system under its operator's control. We denote single target damage probability by $\mathrm{Cdb}$, it can be calculated by

$$
\mathrm{C}_{\mathrm{db}}=\mathrm{P}_{\mathrm{r}} \mathrm{P}_{\mathrm{c}} \mathrm{P}_{\mathrm{b}} \mathrm{P}_{\mathrm{s}}
$$

where $\mathrm{P}_{\mathrm{r}}$ is single target detection probability of shipborne early-warning radar ${ }^{4}, \mathrm{P}_{\mathrm{c}}$ is target acquisition probability of the weapon system's tracking radar, $\mathrm{P}_{\mathrm{b}}$ is control probability of shipborne combat command system, $\mathrm{P}_{\mathrm{s}}$ is single target damage probability.

The reliability of single man-machine system is the multiplication of machine reliability and operator's reliability ${ }^{5}$. $\mathrm{P}_{\mathrm{c}}$ can be calculated by

$$
P_{c}=R_{\text {zht }} R_{\text {zhtry }} P_{\text {sb }}
$$

where $R_{\text {zht }}$ is the operational reliability of shipborne combat command system which can be assessed by using fuzzy comprehensive evaluation method $^{6}, \mathrm{R}_{\mathrm{zhtry}}$ is operator's reliability which can be assessed by using expert evaluation method, $\mathrm{P}_{\mathrm{sb}}$ is the probability of $\mathrm{IFF}^{7}$.

$$
\begin{aligned}
& \mathrm{P}_{\mathrm{b}} \text { can be calculated by }{ }^{8} \\
& \qquad \mathrm{P}_{\mathrm{b}}=\zeta_{\mathrm{bq}} \mathrm{P}_{\alpha}
\end{aligned}
$$


where $\zeta_{\mathrm{bq}}$ is the influence coefficient of marine meteorological environment, $\mathrm{P}_{\alpha}$ is the target acquisition probability of single-scan of the tracking radar antenna.

Usually the main influence factors of $\mathrm{P}_{\alpha}$ is signal-to-interference ratio $(\mathrm{C} / \mathrm{I})$ of tracking radar receiver. $\mathrm{C} / \mathrm{I}$ can be calculated by

$$
C / I=\frac{G_{s}}{G_{z}+\sum G_{j y}+\sum G_{j w}}
$$

where $G_{s}$ is target echo signal power of the receiver ${ }^{9}, G_{z}$ is instantaneous noise power of the receiver ${ }^{10}, G_{j y}, G_{j w}$ are active and passive jamming signal power of the receiver respectively ${ }^{11}$, $\Sigma$ is addition operator.

As reference 8 proposes the method for assessing $\mathrm{P}_{\alpha}$ according to target designate accuracy and target fluctuation characteristics. If $\mathrm{C} / \mathrm{I}$ is in normal distribution, it can assess $\mathrm{P}_{\alpha}$ by using $\mathrm{C} / \mathrm{I}$ instead of signal-to-noise ratio $(\mathrm{S} / \mathrm{N})$ in reference 8.

$\mathrm{P}_{\mathrm{s}}$ can be calculated by

$$
P_{s}=1-\prod_{i=1}^{N_{d m}}\left(1-P_{s i}\right)
$$

where $\mathrm{N}_{\mathrm{dm}}$ is number fired at single target in the process of the weapon fire, $\mathrm{P}_{\mathrm{si}}$ is single target damage probability for No.i which can be calculated by

$$
P_{s i}=R_{s f i} P_{s t i}
$$

where $\mathrm{R}_{\mathrm{sfi}}$ is the flight reliability of No.i which is affected by check-out reliability, fire reliability, guidance reliability and hit reliability. As triangular fuzzy number ${ }^{12}$ can be used to assess flight reliability, we denote triangular fuzzy number of flight reliability by $p_{f}$, it can be calculated by

$$
p_{f}=\min \left\{p_{f j}, p_{f s}, p_{\sim}, p_{\sim}\right\}=\left(a_{f}, m_{f}, b_{f}\right)
$$

where $\mathrm{a}_{\mathrm{f}}$ is the left point of $p_{f}, \mathrm{~m}_{\mathrm{f}}$ is the middle point of $p_{f}, b_{\mathrm{f}}$ is the right point of $p_{f}, p_{f j}, p_{f s}, p_{f x}, p_{f m}$ are the triangular fuzzy numbers of check-out reliability, fire reliability, guidance reliability and hit reliability respectively.

Then $\mathrm{R}_{\mathrm{sfi}}$ can be determined by $p_{f}$ :

$$
\mathrm{R}_{\mathrm{sfi}}=m_{f}
$$

where $\mathrm{P}_{\text {sti }}$ is single target damage probability of No.i in normal flight which can be calculated by

$$
\mathrm{P}_{\text {sti }}=\zeta_{\text {stqi }} \zeta_{\text {stji }} \mathrm{P}_{\text {stli }}
$$

where $\zeta_{\text {stqi }}$ is influence coefficient of marine meteorological environment, $\zeta_{\text {stjc }}$ is influence coefficient of target's antimaneuver, $\mathrm{P}_{\text {stli }}$ is single target damage probability of No.i under electromagnetic interference. Reference 13 provides the method for assessing $\mathrm{P}_{\text {stli }}$ under the conditions of direct damage and fragment damage.

\section{CAPABILITY EVALUATION MODEL OF THE WEAPON FIRE}

We denote the target number in the process of the weapon fire by $\mathrm{N}_{\mathrm{d}}$, $\mathrm{K}$ targets damage probability can be defined by

$$
P(x=K)=a_{K}
$$

where $a_{K}$ is the coefficient of $Z^{K}$ for the equation $\prod_{I=1}^{N_{d}}\left[\left(1-P_{I}\right)+P_{I} z\right]=\sum_{K=0}^{N_{d}} a_{K} z^{K}, P_{I}$ is No.I target damage probability which can be calculated by equation (1), $\mathrm{K} \leq \mathrm{N}_{\mathrm{d}}$.

We denote the expected target damage of the weapon fire by $\mathrm{E}$, it can be calculated by

$$
E=\sum_{I=1}^{N_{d}} P_{I}
$$

\section{SUMMARY}

Usually the operational phase of weapon system includes multiple fires. As the operational capability of the weapon system can be varied with each fire, it proposes the operational capability evaluation method for the weapon system, afterwards it proposes the operational capability evaluation method for the weapon fire taking the factors including single target detection probability of shipborne early-warning radar, control probability of shipborne combat command system, single target acquisition probability of tracking radar, single target damage probability into account. In the end, it can obtain the operational capability evaluation indicators of the weapon system, which can assess the operational capability of single weapon system onboard single surface ship in an operational environment, and provide an operational capability evaluation method for other weapon system.

The development of the proposed method has been an ongoing project, the next step in the research is to implement the proposed method in surface ship air defense operations and exercises.

\section{REFERENCES}

[1] C.G. Zhao, et al. Journal of Projectiles, Rockets, s and Guidance, Vol.21, 31(2001).

[2] C. Jia, Journal of Modern Defence Technology, Vol.33, 22(2005).

[3] L.T. Ma, W.C. Han, Journal of Modern Defence Technology, Vol.32, 11(2004).

[4] L.X. Chen, Effectiveness Evaluation of Network Air Defense Systems, National Defence Industrial Press, China (2007).

[5] P.G. Xu, Tactical Technology, 7(1993).

[6] J.F. Zhang, Applications of Fuzzy Mathematics. Geological Publishing House, China(1998).

[7] C.F. Huang, Telecommunication Engineering, 1 (2000). 
[8] D.K. Barton, Radar System Analysis and Modeling, Artech House Publishers (2004)

[9] R.L. Liang, Shipboard Electronic Countermeasure, Vol.26, 34 (2003).

[10] Y. Jiang, S.H. Huang, Journal of Yangtze University, Natural Science Edition, Vol.1, 17(2004).

[11] Y.B. Liu, et al. Systems Engineering-theory \& Practice, 142 (2008).

[12] L.B. Yang, Y.Y. Gao, Fuzzy Mathematics Theory and Application, South China University of Technology Press, China(1993).

[13] G.Y. Wang, L.D. Wang, Radar Electronic Warfare System Mathematical Simulation and Evaluation, National Defence Industrial Press, China (2004). 